\title{
Erratum zu: Ehrenamtliche Arbeit in politischer Mission oder Engagement für ,gestrauchelte Menschen"?
}

\author{
Diana Düring • Birgit Bütow • Agnès Arp
}

Online publiziert: 26. Januar 2022

(C) Der/die Autor(en) 2021

\section{Erratum zu:}

Soz Passagen 2021

https://doi.org/10.1007/s12592-021-00388-z

In diesem Artikel wurde der Name der Autorin Agnès Arp als Agnes Simone Arp angegeben. Der Originalbeitrag wurde korrigiert.

Open Access Dieser Artikel wird unter der Creative Commons Namensnennung 4.0 International Lizenz veröffentlicht, welche die Nutzung, Vervielfältigung, Bearbeitung, Verbreitung und Wiedergabe in jeglichem Medium und Format erlaubt, sofern Sie den/die ursprünglichen Autor(en) und die Quelle ordnungsgemäß nennen, einen Link zur Creative Commons Lizenz beifügen und angeben, ob Änderungen vorgenommen wurden.

Die in diesem Artikel enthaltenen Bilder und sonstiges Drittmaterial unterliegen ebenfalls der genannten Creative Commons Lizenz, sofern sich aus der Abbildungslegende nichts anderes ergibt. Sofern das betreffende Material nicht unter der genannten Creative Commons Lizenz steht und die betreffende Handlung

Die Online-Version des Originalartikels ist unter https://doi.org/10.1007/s12592-021-00388-z zu finden.

Prof. Dr. Diana Düring $(\bowtie)$

Fachbereich Sozialwesen, Ernst-Abbe-Hochschule Jena, Carl-Zeiss-Promenade 2, 07745 Jena, Deutschland

E-Mail: diana.duering@eah-jena.de

Univ.-Prof. Dr. Birgit Bütow

FB Erziehungswissenschaft, Schwerpunkt Sozialpädagogik, Beratung und Intervention, Paris-Lodron-Universität Salzburg, Erzabt-Klotz-Str. 1, 5020 Salzburg, Österreich

E-Mail: birgit.buetow@plus.ac.at

Dr. Agnès Arp

Oral-History Forschungsstelle, Universität Erfurt, Nordhäuser Str. 63, 99089 Erfurt, Deutschland

E-Mail: agnes.arp@uni-jena.de 
nicht nach gesetzlichen Vorschriften erlaubt ist, ist für die oben aufgeführten Weiterverwendungen des Materials die Einwilligung des jeweiligen Rechteinhabers einzuholen.

Weitere Details zur Lizenz entnehmen Sie bitte der Lizenzinformation auf http://creativecommons.org/ licenses/by/4.0/deed.de. 